\title{
ANTIRODNI POKRETI U 21. STOLJEĆU
}

\section{Maja Gergorić}

Fakultet političkih znanosti, Sveučilište u Zagrebu

E-mail: maja.gergoric@fpzg.hr
DOI: 10.20901/an.17.07

Pregledni rad

Prihvaćeno: lipanj 2020.

Sažetak Početak 21. stoljeća obilježili su pojava i širenje antirodnih pokreta u Europi i Latinskoj Americi. U ovom radu prikazujem literaturu o tim pokretima. Analizirane radove izabrala sam pregledom akademske tražilice Google Scholar, a temeljni kriterij za uvrštavanje u analizu bila je uporaba izraza "antirodni" u naslovu, sažetku ili sadržaju teksta. U analizu su uvrštena šezdeset dva rada, a pregled je strukturiran prema glavnima analitičkim pristupima u studijama društvenih pokreta: prema kulturnim artefaktima i diskurzivnim okvirima, organizacijskim obilježjima i aktivističkim mrežama te strukturama političkih mogućnosti. U članku analiziram i određenje pojmova, dizajn istraživanja, korištene metode i zemljopisnu pokrivenost istraživanjima. Na temelju analize sadržaja zaključujem kako su antirodni pokreti određeni heterogeno, kako su korištene metode i zemljopisna pokrivenost homogeni te kako u analizi prevladavaju kulturni artefakti i diskurzivni okviri.

Ključne riječi društveni pokreti, rodna ideologija, antirodni pokreti politike osporavanja, radikalna desnica

\section{Uvod}

Antirodni pokret suvremena je pojava koja se u posljednje vrijeme ne širi samo zemljopisno, nego se iz prosvjedne pomiče u institucionalnu političku arenu. Proširenost, mobilizacijska uspješnost i raznolikost načina djelovanja potaknuli su velik broj istraživanja te pojave. $U$ ovome radu nastojat ću sustavno prikazati dimenzije pokreta koje su dosad istražene i ukazati na dimenzije koje tek treba istražiti.

Antirodni pokret razvijao se u dvije faze. U prvoj fazi stvoreni su strategija i diskurzivni okvir djelovanja te je počela antirodna mobilizacija. Masovna mo- bilizacija i ubrzano širenje obilježili su drugu fazu. Početak osmišljavanja glavne strategije djelovanja antirodnog pokreta vezuje se za vatikansku konstrukciju pojma "rodna ideologija" (Garbagnoli 2016). "Rodna ideologija", jedan od najrasprostranjenijih i najkorištenijih diskurzivnih okvira za interpretaciju pojma roda kao društvenog konstrukta, suprotna je s vatikanskom shvaćanju spolne različitosti muškaraca i žena. Navedeni okvir nastao je kao reakcija na uvođenje izraza "rod" na Međunarodnoj konferenciji o populaciji i razvoju 1994. u Kairu i Četvrtoj svjetskoj konferenciji o ženama 1995. u Pekingu. U pozadini vatikanske reakcije bila je dvostruka 
strategija. Njezin prvi korak bila je nova definicija roda kojom se taj pojam renaturalizira, odnosno poistovjećuje s biološkim odrednicama muškarca i žene. Osmišljena je nova retorička strategija "rodne ideologije" kojom se Vatikan suprotstavio konstruktivističkom poimanju roda (Garbagnoli 2016). Vatikan je tijekom Pekinške konferencije koristio "progresivni jezik" koji je dotad bio svojstven isključivo feminističkoj teoriji i aktivističkom diskursu. Preuzimanje, a potom i subverziju feminističkog narativa, Vatikan je iskoristio kao alat za suprotstavljanje feminističkim zahtjevima tijekom konferencije (Buss 1998).

Iako je strategija djelovanja vidljiva još od 1995, antirodni pokreti počinju se mobilizirati tek 2004. U Španjolskoj se te godine Katolička crkva, zajedno s konzervativnima društvenim skupinama i političkim strankama, aktivirala protiv donošenja zakona o istospolnim brakovima. Nakon Španjolske, prva faza mobilizacije antirodnih pokreta zahvatila je Hrvatsku 2006, a izrazila se u otporu uvođenju spolnog odgoja u škole. Pokret se potom mobilizira u Italiji 2007. u otporu građanskom partnerstvu i u Sloveniji 2009. u otporu legalizaciji istospolnih brakova (Kuhar i Paternotte 2017).

Drugu, aktualnu fazu mobilizacije antirodnih pokreta obilježio je ubrzan rast u prvom desetljeću 21. stoljeća, pri čemu se 2012. može smatrati prekretnicom. Masovno prosvjedno djelovanje najprije se razvilo u Francuskoj 2012. i 2013. kao reakcija na prijedlog zakona o istospolnim brakovima. Iako u konačnici nije ostvarilo svoje ciljeve, služilo je kao primjer drugima koji su u svojima nacionalnim kontekstima preslikavali francusku strategiju i načine djelovanja. Najočitiji je primjer preslikavanja bio talijanski antirodni pokret. Garbagnoli (2016) zaključuje kako je talijanski antirodni pokret utemeljen na preuzima- nju logotipova, imena i stilova glavnih francuskih antirodnih aktivnosti. Talijanski se pokret 2013. mobilizirao protiv zakona o suzbijanju diskriminacije na temelju seksualne orijentacije i rodnog identiteta, kao i protiv implementacije obrazovnih alata kojima bi se ostvarila rodna ravnopravnost i spriječilo zlostavljanje LGBTQ-osoba u osnovnim školama (Garbagnoli 2017). Antirodni pokret pojavljuje se 2012. i u Poljskoj, a bio je usmjeren protiv ratifikacije Konvencije Vijeća Europe o sprječavanju i borbi protiv nasilja nad ženama i nasilja u obitelji ili, poznatije, protiv Istanbulske konvencije (Graff i Korolczuk 2017). Te godine antirodni pokret intenzivnije se aktivira i u Hrvatskoj oponirajući zdravstvenom odgoju u školama (Hodžić i Štulhofer 2017). U Sloveniji je istodobno iniciran referendum protiv izmjena Zakona o braku i obiteljskim odnosima kojima se planirala uvesti bračna jednakost u slovensko zakonodavstvo (Kuhar 2017). U Mađarskoj se antirodni pokret nije razvio, jer se antirodni diskurs 2014. počeo koristiti u političkoj areni kako bi se oponiralo dvama izvješćima Europskog parlamenta: Izvješću o spolnom i reproduktivnom zdravlju i pravima te Izvješću o planu EU-a protiv homofobije i diskriminacije na temelju spolne orijentacije i rodnog identiteta, koja su poznatija kao izvješća Estrela i Lunacek. (Kováts i Pető 2017). Prva i druga faza pokreta ne razlikuju se samo prema zemljopisnoj rasprostranjenosti i snazi pokreta nego i prema korištenju diskurzivnog okvira "rodna ideologija", koji se uopće nije koristio u prvoj fazi da bi postao dominantnim u kampanjama u drugoj fazi razvoja pokreta (Kuhar i Paternotte 2017).

Unatoč tome što su korijeni početne mobilizacije antirodnih pokreta u zapadnoj Europi, u drugoj fazi djelovanja oni su bili intenzivniji u državama istočne i jugoistočne Europe. Osim toga, 
antirodni pokreti nisu ograničeni na Europu nego su se pojavili i u Latinskoj Americi gdje su najčešće bili usmjereni protiv obrazovnih reformi i sadržaja koji se tiču roda ili suzbijanja homofobije. $\mathrm{Na}$ tom se potkontinetu antirodni pokret pojavio 2011. u Brazilu, 2016. u Kolumbiji, Meksiku i Peruu, a 2017. u Paragvaju (Miskolci 2018).

\section{Teorijski okvir}

Početak razvoja analitičkih pristupa društvenim pokretima i politikama osporavanja vezuje se za model političkog procesa (Goodwin i Jasper 2015). U navedenom je modelu težište analize društvenih pokreta na političkom kontekstu, odnosno na političkim mogućnostima i ograničenjima koja određuju načine na koje pokreti djeluju. Kao jedan od predstavnika modela političkog procesa, McAdam shvaća važnost i subjektivnog značenja koje sudionici pokreta pridaju svojem djelovanju te analitički uzima u obzir i tu dimenziju društvenih pokreta. Kasnije će se to nazvati procesom uokvirivanja, odnosno stvaranjem diskurzivnih okvira i oblikovanjem ključnih poruka kojima pokret pokušava proizvesti mobilizaciju za vlastite ciljeve. Da bi u tome uspjeli, pokreti moraju razviti svoje središnje ideje, okvire, koje će jedan dio javnosti razumjeti i poduprijeti (Kriesi 2013). Analize društvenih pokreta kroz politički kontekst i proces uokvirivanja stvaraju temelje za buduću kategorizaciju analitičkih pristupa društvenim pokretima. McAdam i suradnici (1996) predlažu sintezu različitih analitičkih pristupa društvenim pokretima i politikama osporavanja. Riječ je o trima dimenzijama ili pristupima analizi: strukturi političkih mogućnosti, aktivističkim mrežama te kulturnim artefaktima i uokvirivanju.

Prvi analitički pristup, struktura političkih mogućnosti, prema McAdamu i suradnicima (1996) odnosi se na per- spektivu društvenih pokreta kao aktera oblikovanih političkim mogućnostima i prijetnjama svojstvenima nacionalnom kontekstu unutar kojega djeluju. Goldstone i Tilly (2001) mogućnosti shvaćaju kao vjerojatnost uspjeha u postizanju željenog ishoda društvenog pokreta. Uspjeh postaje vjerojatniji se u trenutku pomicanja ravnoteže političkih i ekonomskih resursa između države i pokreta, slabljenja sposobnosti države da nagradi svoje sljedbenike te uskraćivanja unutarnje ili vanjske potpore režimu. Tarrow (2011) izlaže niz čimbenika koji neposredno omogućuju uspjeh nekoga društvenog pokreta: pristup sudjelovanju koji se otvara novim akterima, političko prestrojavanje unutar političke zajednice, dostupnost utjecajnih saveznika i sukobe unutar postojećih elita. Osim toga, unutar strukture političkih mogućnosti važno je definirati i prijetnje $s$ kojima se društveni pokreti suočavaju. Goldstone i Tilly (2001) prijetnje vide u obliku troškova ili rizika djelovanja, odnosno nedjelovanja.

Drugi analitički pristup društvenim pokretima čine aktivističke mreže koje podrazumijevaju i formalne organizacije i neformalne mreže. Teoretičari aktivističkih mreža smatraju kako su upravo osobne veze među potencijalnim aktivistima preduvjet nastanka društvenog pokreta. Ostvareni bliski odnosi među potencijalnima i postojećim članovima pokreta, kao i formirane organizacije kojima zainteresirane osobe mogu pristupiti jesu preduvjeti lakše mobilizacije pristaša i konačne izgradnje pokreta (Goodwin i Jasper 2015).

Treći analitički pristup društvenim pokretima i politikama osporavanja čine kulturni artefakti i uokvirivanje. Unutar tog pristupa analiziraju se svjesni i strateški napori određene skupine ljudi da osmisle zajedničko razumijevanje vanjskog svijeta, kao i samih sebe, kako bi legitimirali vlastite kolektivne akcije i 
motive članova pokreta da u njima sudjeluju (McAdam i dr. 1996.) Prema Snowu i Benfordu (1992), proces uokvirivanja uključuje izgradnju interpretacijske sheme koja pojednostavnjuje i sažima vanjski svijet. Osmišljeni diskurzivni okviri trebaju naglasiti ozbiljnost društvenog stanja i nepravde u njemu, ali i redefinirati ono što se prije smatralo nepovoljnim, ali podnošljivim, kao nešto što je nepravedno i nepodnošljivo (Tarrow 2011). Pokreti, također, definiraju i grade kolektivni identitet kako bi se iscrtale granice koje određuju tko smo "mi", a tko su "oni". Kao posljednji način stvaranja značenja, pokreti izražavaju, obuhvaćaju i oblikuju emocije kako bi mobilizirali sljedbenike.

Uz tri navedena analitička pristupa, koji čine glavni tipološki okvir za pregled literature, skrećem pozornost i na ostale dimenzije $\mathrm{u}$ istraživanjima antirodnih pokreta. To se ponajprije odnosi na definicijske probleme, dizajn i metode istraživanja. Posljednja dimenzija tiče se zemljopisne pokrivenosti istraživanjima jer se uobičajeno pretpostavlja da su društvene znanosti eurocentrične (Wallerstein 1997). Navedeni kriteriji analize odabrani su kako bi se što podrobnije prikazalo sadašnje stanje znanja o antirodnim pokretima, posebice $s$ obzirom na osnovne postavke analiziranih istraživanja: definiciju fenomena, odabir fokusa unutar tematskog polja antirodnih pokreta te dizajn i metode istraživanja.

\section{Odabir istraživanja}

U pregledne radove uvršteni su članci o antirodnim pokretima do kojih se može doći pomoću tražilice Google Scholar. U pretraživanju je korištena ključna riječ antirodni (anti-gender), budući da je to najčešća oznaka pokreta, neovisno o tome jesu li autori i autorice suglasne s njegovim pojmovnim određenjem ili ne. Kako je korištena ključna riječ na engleskom jeziku, pregled je bio ograničen na literaturu objavljenu na engleskom jeziku.

Budući da je riječ o novijem, nedovoljno istraženom pokretu, razdoblje pretrage nije specificirano kako bi se obuhvatili svi radovi o toj temi. Istraživanje je provedeno od prosinca 2019. do veljače 2020. Odabrani su samo znanstveni radovi, odnosno izvorni znanstveni članci, monografije i zbornici.

Kvalitativna analiza sadržaja obuhvatila je šezdeset dva članka i poglavlja u knjigama, koji su odabrani prema opisanoj metodologiji. U analizi je obrađeno pedeset članaka, dok su u zborniku The Anti-Gender Movement in Comparative Perspective (Kuhar i Paternotte 2017) zasebno obrađena sva poglavlja. Svaka je jedinica analize potom kategorizirana prema korištenim analitičkim pristupima društvenim pokretima i politikama osporavanja, pojmovnoj usuglašenosti, dizajnu istraživanja i korištenim metodama te zemljopisnoj pokrivenosti istraživanjima.

Iako razdoblje pretrage nije bilo zadano, utvrđeno je kako se radovi koji tematiziraju antirodne pokrete mogu naći tek od 2014. Godine 2017. primjetan je nagli porast broja istraživanja o antirodnim pokretima pa je te godine objavljeno najviše istraživanja te teme, kao i najopsežnije djelo o antirodnim pokretima (Kuhar i Paternotte 2017). Broj objavljenih istraživanja o antirodnim pokretima narednih se godina postupno smanjivao, što je vidljivo iz grafikona 1.

Od 62 odabrana rada, 21 objavljen je kao poglavlje u sedam različitih knjiga. No samo je jedna knjiga u cijelosti posvećena antirodnim pokretima (Kuhar i Paternotte, 2017). Dvije knjige smještaju antirodne pokrete u kontekst širih političkih kretanja kao dio radikalnih 
Grafikon 1. Broj radova o antirodnim pokretima 2014-2020.

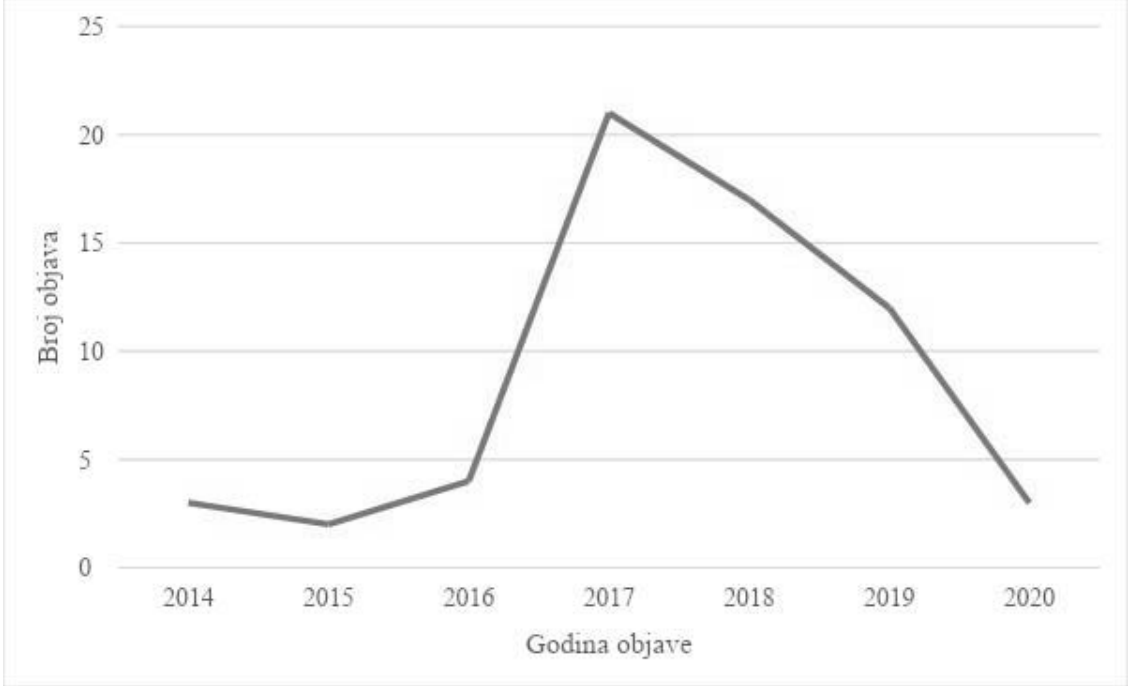

desnih politika (Köttig, Bitzan i Petö 2017) ili kao dio različitih vrsta opozicije politikama rodne ravnopravnosti (Verloo 2018b). U ostalim knjigama antirodni su pokreti sporedni fenomeni. Primjerice, $u$ jednoj se knjizi analiziraju globalne kulture osporavanja (Peeren i dr. 2018), u drugoj se istražuje rodno uvjetovano nasilje u Italiji (Bandelli 2017), u trećoj se analiziraju sjecišta globalnoga i lokalnog u književnosti i jeziku (Mehta 2018), dok posljednja služi kao priručnik za interdisciplinarnu rodnu analizu (Kortendiek, Riegraf i Sabisch 2019).

Među odabranim radovima najviše je (42) članaka u časopisima. Odabrani članci nisu objavljeni unutar specifičnog područja, a time ni časopisa koji su specijalizirani za antirodne pokrete. Članci o antirodnim pokretima objavljeni su u 34 časopisa. U samo četiri od tih časopisa objavljeno je više od jednog članka o antirodnim pokretima, i to uvijek u sklopu posebnih izdanja. Riječ je o časopisima Religion \& Gender (Garbagnoli 2016; Kaoma 2016; Pető 2016), Signs: Journal of Women in Culture and Society (Korolczuk i Graff 2018; Corredor
2019; Case 2019), European Journal of Politics and Gender (Donà 2020; Korolczuk 2020; Roggeband i Krizsán 2018) i Politics and Governance (Krizsan i Roggeband 2018; Verloo i Paternotte 2018; Verloo 2018a).

Osim što se tema antirodnih pokreta pokazala važnom i zanimljivom različitim časopisima, vidljivo je da je zainteresirala i velik broj autora i autorica. Antirodne pokrete istraživala su 64 autora i autorica. Među odabranim radovima samo je sedam autora i autorica objavilo više od tri rada o toj temi. Riječ je o Romanu Kuharu i Davidu Paternotteu (Kuhar i Paternotte 2017; Paternotte i Kuhar 2018; Bracke, Dupont i Paternotte 2017; Kuhar 2017; Kuhar i Zobec 2017; Verloo i Paternotte 2018), Eszter Kováts i Andrei Pető (Kováts i Pető 2017; Kováts 2017, 2018; Pető, 2016, 2019; Grzebalska i Pető 2018), Agnieszki Graff i Elżbieti Korolczuk (Graff 2014; Graff i Korolczuk 2017; Korolczuk i Graff 2018; Korolczuk, 2020) te Conny Roggeband (Krizsán i Roggeband 2018; Roggeband 2018; Roggeband i Krizsán 2018). 


\section{Analiza istraživanja} antirodnih pokreta

Analizirane su četiri kategorije istraživanja o antirodnim pokretima: (a) analitički pristupi društvenim pokretima i politikama osporavanja, (b) pojmovna usuglašenost, (c) dizajn i metode istraživanja i (d) zemljopisna pokrivenosti istraživanjima.

\section{Analitički pristupi}

Novija istraživanja društvenih pokreta koriste jedan od triju analitičkih pristupa. U sljedećim pododjeljcima prikazujem rezultate pregleda literature $s$ obzirom na diskurzivne okvire, oblike organizacije pokreta i strukturu političkih mogućnosti i prijetnji.

\section{Kulturni artefakti i uokvirivanje}

Kao što je vidljivo iz tablice 1 , u analizi antirodnih pokreta najčešće su korišteni kulturni artefakti i uokvirivanje. U polovici pregledanih radova oni se analiziraju iz perspektive kolektivnih procesa društvenih konstrukcija u kojima društveni pokreti svoje djelovanje objašnjavaju ostalima ili pomoću kojih s pripadnicima vlastitog pokreta izgrađuju zajednički identitet. Unutar istraživanja koja se bave diskurzivnim uokvirivanjem antirodnih pokreta, najviše je analiziran diskurzivni okvir "rodne ideologije". Riječ je o najzastupljenijemu diskurzivnom uokvirivanju, čije izvore Garbagnoli (2016) nalazi u vatikanskim dokumentima. Prije oblikovanja aktualnog oblika i značenja okvira "rodne ideologije", prve naznake "rata protiv roda" pojavljuju se u promišljanjima Josepha Ratzingera o rodu, odnosno u knjizi Ratzingerovo izvješće (1985). U njoj Ratzinger iznosi teze o opasnosti suvremenog feminizma i njegova zahtjeva za potpunom ravnopravnošću muškaraca $\mathrm{i}$ žena, odnosno onime što antirodni pokret naziva "rodnom ideologijom" (Case
2019). Početkom devedesetih godina 20. stoljeća Vatikan nastavlja osmišljavati antirodni diskurs, reagirajući na percipiranu prijetnju od denaturalizacije spolnog poretka za koju su se zauzimale feminističke teoretičarke i aktivistice. Vatikansko uokvirivanje konstruktivističkog shvaćanja roda kao "rodne ideologije" napravljeno je zato da bi se ta "ideologija" prikazala kao prijetnja vatikanskom shvaćanju roda kao spolne različitosti $^{1}$ (Garbagnoli 2016).

Termin "rodna ideologija" služio je antirodnom pokretu da kreira jedinstvena neprijatelja, ujedini religiozne i nereligiozne aktere radi široke mobilizacije, stvara moralnu paniku u javnoj sferi te sprječava pravne i društvene reforme sustava seksualnoga i reproduktivnog zdravlja i prava, kao i prava LGBT osoba. Najvećim uspjehom navedenoga diskurzivnog okvira Garbagnoli (2016) smatra nastanak rodnoga naspram antirodnog rascjepa u javnom prostoru. Uspostavljena je simetrija između dviju disparatnih strana i diskursa definirana vatikanskim terminima. Postojanje antirodne fronte proizvodi vjerovanje u postojanje prorodne fronte.

Sljedeći je najčešći diskurzivni okvir antikolonijalni okvir. On je specifičan za analizu antirodnih pokreta $\mathrm{u}$ istočnoj i jugoistočnoj Europi, ali i u Latinskoj Americi. Poput okvira "rodne ideologije", i antikolonijalni okvir prisutan je u djelovanju antirodnog pokreta od njegovih početaka. Već u prvim raspravama o konceptu roda na Četvrtoj svjetskoj konferenciji UN-a o ženama 1995. u Pekingu, opasnost "rodne ideologije" prikazana je upravo kroz prijetnju od kolonijalizma. S obzirom na to da su u

\footnotetext{
Spolna različitost, odnosno jednakost $\mathrm{u}$ dostojanstvu, ali različitost i komplementarnost u prirodi zamijenile su prethodno vatikansko tumačenje rodnih uloga kroz podređivanje žena muškarcima (Garbagnoli 2016).
} 
Tablica 1. Analitički pristupi antirodnim pokretima

\begin{tabular}{ccc}
\hline $\begin{array}{c}\text { Struktura političkih } \\
\text { mogućnosti }\end{array}$ & $\begin{array}{c}\text { Kulturni artefakti i } \\
\text { uokvirivanje }\end{array}$ & $\begin{array}{c}\text { Aktivističke } \\
\text { mreže }\end{array}$ \\
\hline $23.2 \%$ & $50.0 \%$ & $26.8 \%$ \\
\hline
\end{tabular}

fokusu konferencije bili razvojni programi koji pomažu ženama u siromaštvu, konferencijski narativ predstavnice Vatikana Mary Ann Glendon temeljio se upravo na kolonijalističkom pristupu UN-a zemljama u razvoju posredstvom "rodne ideologije". Glendon je kritizirala pekinške dokumente kao oblik "novog kolonijalizma" kojemu je cilj kontrola, a ne oslobođenje žena. "Novi kolonijalizam" vidljiv je u pokušaju povezivanja razvojne pomoći i "programa koji vrše pritisak na siromašne žene kako bi izvršile pobačaj, sterilizaciju i koristile rizične metode kontracepcije" (nav. u: Case 2019: 643). Antikolonijalni okvir koristio je i Jorge Mario Bergoglio, odnosno papa Franjo, nazivajući "rodnu ideologiju" ideološkim kolonizatorom. Ta je usporedba nastala tijekom razdoblja liberalizacije zakonodavstva u Argentini kada su usvojeni zakoni o istospolnom braku (2010) i legalizaciji plaćenoga nadomjestnog majčinstva (2011), a promijenjen je zakon o rodnom identitetu (2012) (Case 2019). Upravo je naglasak pape Franje "na ideološkoj kolonizaciji - bilo pritiskom donatorskih država, nevladinih udruga, multinacionalnih ili nadnacionalnih organizacija poput Ujedinjenih naroda i Europske unije bilo pravilima nacionalnih ministarstava obrazovanja - našao odjeka u navodno koloniziranim državama, od globalnog Juga do istočne Europe" (Case 2019: 650).

Unutar antikolonijalnog okvira Litvi Buschmann (2017) utvrdila je kako je koncept "rodne ideologije" sličan konceptu komunizma. Oba se koncepta predstavljaju kao ideologije koje žele zavladati politikom i zakonima, izjednačavaju kolonijalno ponašanje Europske unije s opresivnim politikama Sovjetskog Saveza, a konačni je zajednički cilj stvaranje novog društva.

Analizirajući glavne tekstove europskih antirodnih teoretičarki, poput Gabriele Kuby i Marguerite Peeters, Korolczuk i Graff (2018) tvrde kako upravo antikolonijalni okvir ima ključnu ulogu u antirodnom ratu protiv roda i u suvremenom oživljavanju neliberalnog populizma. Prema mišljenju tih autorica, antikolonijalni okvir antirodnog pokreta zasniva se na trima elementima koji čine ideološku srž pokreta. Prvi element čini sklop uvjerenja o prirodi čovjeka, prirodnom zakonu i ljudskom dostojanstvu koji su, s jedne strane, u skladu s kršćanskom dogmom, dok su, s druge strane, suprotni društvenom konstruktivizmu. Drugi element uključuje pesimistični i antimoderni narativ o intelektualnoj, kulturnoj i društvenoj povijesti Zapada. Smatra se kako je Zapad degenerirao i kako propada pod utjecajem zapadnjačkih ličnosti i teorija - od Karla Marxa, Friedricha Engelsa, Sigmunda Freuda, frankfurtske škole do feminizma i postmodernizma, te posebice pod utjecajem Margaret Sanger, Margaret Mead i Alfreda Kinseya. Posebna se pozornost posvećuje antiratnom pokretu 1968. i seksualnoj revoluciji kao začecima "rodne ideologije". No autorice misle da su antirodni pokreti u postsocijalističkim državama i državama globalnog Juga otporni na zapadnjačku kulturnu promjenu. Upravo one mogu spasiti Zapad 
od duhovne i demografske propasti braneći izvorne, univerzalne zapadnjačke vrijednosti koje podrazumijevaju kršćanske vrijednosti i civilizaciju. Trećim i najvažnijim elementom antikolonijalnog okvira autorice smatraju alarmantno shvaćanje globalne raspodjele moći $\mathrm{u}$ antirodnom pokretu, prema kojemu su neomarksistički globalisti preuzeli svijet ucjenama i manipulacijama koje su maskirali dobronamjernim razgovorima o javnom zdravstvu i ljudskim pravima. Transnacionalne institucije, poput Ujedinjenih naroda i Europske unije, antirodne pokrete vide kao ključna mjesta neokolonijalne moći. Povezanost tih institucija i lokalnoga civilnog društva devedesetih godina antirodni pokret uzima kao ishodište kritike postojeće strukture civilnog društva u postsocijalističkoj Europi i zemljama u razvoju. Kao antiteza postojećemu civilnom društvu nastaje konzervativna, neliberalna verzija civilnog društva, koja svoju legitimnost temelji na pozivanju na volju naroda, izraženu u prosvjedima i na referendumima koje organizira antirodni pokret.

\section{Aktivističke mreže}

Nešto više od četvrtine istraživanja razmatra antirodne pokrete analizom njihovih aktivističkih mreža. Analiza mreža najviše se fokusirala na ulogu Katoličke crkve, ali i drugih crkava, poput Evangeličke crkve u Latinskoj Americi, kao i na ulogu radikalnih desnih političkih stranaka i političara.

Najširu klasifikaciju aktera daju Kuhar i Paternotte (2017) na temelju komparacije trinaest nacionalnih antirodnih pokreta. Antirodni pokreti sastavljeni su od kompleksnih konstelacija aktera koji uključuju obiteljske udruge, skupine koje se protive pobačaju, vjerske konzervativce, visoke dužnosnike Katoličke crkve, nacionaliste i populiste te krajnje desničarske skupine. Dijele se na aktere koji su postojali i djelovali prije nastanka antirodnog pokreta (poput skupina koje se protive pobačaju), nove aktere koji su nastali kako bi se borili protiv "rodne ideologije" i na raznovrsne aktere koji variraju od akademičara preko političara do medija.

Hennig (2018) analizira savezništvo europskih vjerskih i političkih desnih aktera protiv rodno osjetljivih reformi. Tvrdi kako se taj savez zauzima za borbu protiv pojma roda koji je suprotan njegovu naturalističkome i hijerarhijskom razumijevanju rodnih odnosa i antipluralističkoj koncepciji homogenog društva. Vjerske aktere analizira i Carnac (2020), koji tvrdi kako je Katolička crkva odigrala ključnu ulogu u francuskome antirodnom pokretu. Prema mišljenju toga autoru, glavni se ishod antirodnog pokreta ne izražava u njegovim učincima na političke protivnike nego u utjecaju na katoličku zajednicu. Predstavljajući rod kao imaginarnog neprijatelja, francuski antirodni pokret utjecao je na jačanje katoličkog identiteta i osjećaja zajedništva. No takva je strategija istodobno imala i negativan učinak na katoličku zajednicu tako što je oživjela stare sukobe unutar Katoličke crkve i ubrzala unutarnju podjelu katoličke zajednice.

Osim Katoličke crkve, desnih interesnih skupina i političara, $u$ antirodnom pokretu djeluju i neopentekostalski evangelici. Miskolci (2018) ističe kako se savez tih aktera pokazao korisnim i za religijske i za sekularne aktere. Religijski i politički akteri postali su saveznici u sprječavanju širenja prava i rodne ravnopravnosti koje smatraju suprotnima njihovim načelima i ograničenjima njihovu djelovanju. Taj savez koristi i sekularne desne, obično populistične i neoliberalne interesne skupine, pomažući im u provođenju neoliberalnih ekonomskih politika. 
Stranke desnice analizirala je Donà (2020), koja tvrdi kako se populistička talijanska stranka Sjeverna liga iz etnoregionalne stranke transformirala $\mathrm{u}$ radikalnu desnu populističku stranku. ${ }^{2}$ Liga je, u savezništvu s antirodnim pokretom, dovela do nazadovanja politika rodne ravnopravnosti. Oltenau (2017) je proučavala pristup radikalne desne Slobodarske stranke Austrije (FPÖ) rodnim pitanjima i zaključila kako se antirodni stav stranke očituje i u individualnom djelovanju njezinih političarki, poput Barbare Rosenkranz, ali i u stavovima stranke koja rodnu ravnopravnost smatra suprotnom obiteljskim politikama. O ekstremno desnim populističkim strankama pisala je Verloo (2018a), proučavajući nizozemske stranke i njihov diskurzivni napad na rodnu ravnopravnost. Analizirajući Stranku za slobodu (PVV) i Forum za demokraciju (FvD), autorica zaključuje kako one zastupaju femonacionalistički i homonacionalistički stav o rodnoj i seksualnoj ravnopravnosti. Iako rodnu ravnopravnost smatraju ostvarenom u nizozemskoj naciji, istovremeno je smatraju ugroženom od strane muslimanskih nizozemskih građana, odnosno onih koji, prema njihovu mišljenju, nisu dio nizozemske nacije. Antirodni stav analiziranih stranaka autorica vidi i u njihovu glasovanju protiv rodno ravnopravnih mjera i stalnom poricanju postojanja rodne neravnopravnosti u Nizozemskoj.

\section{Struktura političkih mogućnosti}

Uzrocima nastanka antirodnih pokreta najčešće se smatraju političke i ekonomske krize. Pišući o uzrocima nastanka antirodnog pokreta, Kováts (2017) tvrdi kako je on istodobno i simptom i posljedica šire socijalno-ekonomske, političke i kulturne krize liberalne demokracije. U jednome kasnijem radu Kováts (2018)

2 O ideološkoj i političkoj transformaciji te stranke v. Raos (2018). taj argument proširuje i pokazuje kako antirodni pokret osporava liberalnu demokraciju i propituje dva temeljna konsenzusa liberalne demokracije. Prvi je neoliberalni konsenzus koji u zapadnoj Europi izgleda kao pakt stranaka desnoga i lijevog centra koje prikazuju neoliberalni oblik globalizacije kao jedinu opciju. Drugi je konsenzus o ljudskim pravima, koji pretpostavlja postojanje određenih prava kao moralnih vrijednosti o kojima se ne može pregovarati. Antirodni pokret kao odgovor na krizu vidi i Szelewa (2014) koja je, analizirajući politike skrbi za djecu u Poljskoj, zaključila kako je ekonomska kriza Katoličkoj crkvi poslužila kao pozadina za napad na kategoriju roda. Za Korolczuk (2020), antirodna retorika zapravo je kritika individualizma i neoliberalne globalizacije. Autorica tvrdi kako je uspon desnih stranaka u Poljskoj povećao mogućnosti za politički uspjeh ultrakonzervativnih organizacija, nakon čega je intenzivirana retorika o kulturnom ratu i povećan broj novih antirodnih inicijativa i aktivista. Dokaze za to da su se prostori političkih mogućnost antirodnih pokreta proširili, autorica prepoznaje i u činjenici da su predstavnici tih pokreta ušli i u političku arenu te da djeluju i unutar državnih struktura.

S druge strane, Butler (2019b) osporava tvrdnje o povijesnom razvoju neoliberalizma i financijalizacije kao glavnih i jedinih uzroka antirodnog pokreta. Financijalizacija podrazumijeva naglasak na povećanje kapitala koji ugrožava opstank sigurnih oblika zaposlenja. Ona tvrdi kako su neoliberalizam i financijalizacija dijelovi kompleksnije mreže unutar koje se nacionalizam, rasizam i militarizam udružuju s propagandom antirodnih pokreta. Odnosno, što se više smanjuje proračun socijalnih službi u korist privatnih usluga i izdvajanja, to je jača uloga Evangeličke i Katoličke cr- 
kve zahvaljujući tome što daju socijalne usluge i smjernice za moralni poredak.

Grzebalska i Pető (2018) ističu važnu ulogu rodnih politika koje su pridonijele artikulaciji protuhegemonijskih projekata desnih aktera. Upravo jedan takav program neliberalne demokracije u srednjoj Europi nastao je u kontekstu neuspješnoga liberalno- demokratskog projekta sa slabima i podijeljenim progresivnim strankama i slabima nacionalnim državama koje je značajno oslabjela neoliberalna globalizacija. Neliberalne demokracije temelje se na iskorištavanju i iscrpljivanju postojeće institucionalne strukture liberalne demokratske države, što uključuje prisvajanje jezika i infrastrukture ljudskih prava i rodne ravnopravnosti, izgradnju paralelnoga civilnog društva i zlouporabu demokratskih procedura kako bi poslužile vladajućoj eliti i njezinim saveznicima.

Velmet (2019) tumači uspjeh estonskoga antirodnog pokreta kao posljedicu napetosti između nadnacionalne vladavine i nacionalne suverenosti, odnosno kao izraz problema koji se u Estoniji ponovno pojavio nakon hladnog rata. Mobilizacija antirodnog pokreta u Estoniji, kao i u Češkoj, Slovačkoj i skandinavskim državama, posebno je zanimljiva s obzirom na to da je riječ o državama u kojima je religija povijesno imala marginalnu političku ulogu. U Estoniji osnova mobilizacije nije religija nego strah od nadnacionalnog autoriteta.

\section{Pojmovi i definicije}

Pregledom članaka o antirodnim pokretima ustanovljena je izrazita multidisciplinarnost radova. Većina radova nalazi se na područjima teologije, lingvistike, prava, politologije (javnih politika) i sociologije, pri čemu se izrazito mali broj, manje od jedne petine, članaka oslanja na teorije društvenih pokreta. Posljedice disiciplinarne raznolikosti očituju se $u$ različitim konceptualizacijama i definicijama antirodnih pokreta.

Neusuglašenost pojmovi vidljiva je $u$ iznimno velikom broju naziva antirodnih pokreta. U uzorku koji sam analizirala koristi se čak trideset jedan termin. Osim naziva antirodni pokret (Kuhar i Zobec 2017), najčešće su korišteni termini antirodna mobilizacija (Gennero 2017), antirodna kampanja (Korolczuk 2020), antidženderizam (Buschmann 2017), antifeministički pokret (Szelewa 2014), antirodni aktivizam (Kováts 2017), antirodne pozicije (Kalil 2019) i nazadovanje politika rodne ravnopravnosti (Krizsan i Roggeband 2018).

Različita određenja proizlaze iz suprotstavljenih shvaćanja antirodnih pokreta, koja ću kategorizirati na temelju dviju odrednica. Prva odrednica odnosi se na neovisnost fenomena, odnosno na to smatra li se on zasebnom pojavom ili dijelom nekoga šireg fenomena. Druga se odrednica odnosi na shvaćanje same prirode fenomena, to jest na to smatra li se da je on izravna politička opozicija ili nadilazi izravnu opoziciju. Na temelju tako definiranih odrednica, identificirana su četiri pristupa antirodnim pokretima. Prvi i najčešći jest antirodni pristup unutar kojega se nalazi čak 41 članak. Slijedi pristup koji antirodni pokreti smatra dijelom radikalne, populističke, ekstremne ili religijske desnice, a zastupljen je u sedam radova. Četiri istraživanja antirodne pokrete smatraju antifeminističkim fenomenom, a šest ih određuje izvan navedenih kategorija.

Antirodna skupina shvaća antirodni pokret kao neovisan fenomen koji u određenim kontekstima može imati doticaj s drugim pokretima ili ideologijama (poput radikalnoga desnog populizma), ali ga je ipak potrebno proučavati kao zaseban fenomen (Paternotte i Kuhar 2018). Ta skupina nema jedinstveno shvaćanje antirodnog fenomena, bilo 
kao pokreta, mobilizacije, kampanje, aktivizma, prosvjeda, demonstracije bilo kao pozicije, diskursa i ideologije.

Szelewag (2014), Roggeband (2018) i drugi autori koji fenomen shvaćaju antifeminističkim, percipiraju ga kao zasebnu pojavu. No antifeministi smatraju kako je fenomen nastao kao direktna opozicija feminističkom pokretu, odnosno feminističkim i seksualnim politikama.

Antirodni pokret često se definira i kao radikalna, populistička, ekstremna i/ili religijska desnica. Percipira se kao dio širega političkog kretanja ili ideologije, u ovom slučaju kao dio radikalne, populističke, ekstremne i/ili religijske desnice, koji nadilazi izravnu opoziciju feminističkom pokretu. Fenomen se definira kao desni populistički pokret (Harsin 2018a), ekstremni desni populizam (Verloo 2018a), politički i religijski fundamentalizam (Perintfalvi 2016), antirodna kampanja religijske desnice (Graff 2014) ili radikalni desni kršćanski napad na rod (Butler 2019a).

Naposljetku, antirodni fenomeni određuju se izvan prethodno opisanih kategorija. Harsin (2018b) antirodni pokret shvaća kao pokret obiteljskih vrijednosti, Grzebalska i Pető (2018) kao neliberalnu demokraciju koju definira kao nacionalistički odgovor većine na neuspjehe globalnoga neoliberalnog modela, Browne i Nash (2017) kao heteroaktivizam koji označava novi oblik suprotstavljanja rodnima i seksualnim pravima, a Henning (2018) kao političku rodofobiju koja služi kao pejorativna referencija za feministice, LGBT-zajednicu te institucije i osobe koje podržavaju politike suzbijanja diskriminacije.

\section{Dizajn i metode istraživanja}

Početna klasifikacija pokazala je da su analizirani radovi teorijski (46 posto) i empirijski (54 posto) ujednačeni. Dubljim uvidom u metode empirijskih istraživanja može se ustanoviti i metodološka homogenost.

Većinom su korištene kvalitativne metode, dok je u samo jednome članku korištena kvantitativna metoda. Riječ je o članku u kojemu se kroz dva anketiranja katolika u Poljskoj mjerila povezanost teorija urote o rodu s defenzivnošću prema vlastitoj vjerskoj skupini (Marchlewska i dr. 2019). To je ujedno i jedini članak koji se antirodnim fenomenom bavi iz perspektive potražnje. Istraživanja koja pokrete proučavaju iz perspektive potražnje fokusiraju se na analizu podrške koju stanovništvo daje određenom pokretu, što u slučaju Marchlewske i suradnika (2019) znači da analiziraju stavove podržavatelja antirodnih pokreta. To je istraživanje pokazalo da postoji povezanost urotničkih uvjerenja o rodu i defenzivne identifikacije s vlastitom vjerskom skupinom. Ta povezanost čini članove skupine posebno osjetljivima na vanjske prijetnje, poput teorija urota o rodu. Ostali članci antirodne pokrete analiziraju iz perspektive ponude putem novinskih članaka, priopćenja za javnost, političkih govora članova pokreta, objava na društvenim mrežama (Lavizzari i Prearo 2018; Kuhar i Zobec 2017; Harsin 2018b) ili javnih rasprava i politika (Roggeband i Krizsán 2018; Szelewa 2014).

$\mathrm{U}$ analizama antirodnih pokreta korišteno je 16 kvalitativnih metoda. Prevladava kritička analiza diskursa (Kuhar i Paternotte 2017; Kuhar i Zobec 2017; Harsin 2018b; Spallaccia 2019), a slijedi, mnogo rjeđa, analiza teksta (Korolczuk i Graff 2018; Roggeband i Krizsán 2018; Buschmann 2017; Odrowąż-Coates 2015).

\section{Komparativne analize antirodnih pokreta}

Dominantna većina članaka temelji se na studiji slučaja, odnosno na analizi samo jedne države ili pokreta, a ma- 
nje od 15 posto članaka zasnovano je na komparativnoj analizi dvaju ili više slučajeva. Antirodni pokreti pogodni su za primjenu komparativne analize $s$ obzirom na to da je riječ o suvremenom fenomenu koji se pojavljuje u različitim dijelovima svijeta (Miskolci 2018, Kaoma 2016). Ipak se najčešće koriste studije slučaja ili deskriptivne komparacije više slučajeva (Miskolci 2018; Case 2019; Perintfalvi 2016; Kaoma 2016; Browne i Nash 2017).

Kada je riječ o komparativnoj analizi antirodnih pokreta, najveći broj slučajeva obuhvatili su Kuhar i Paternotte (2017): deset nacionalnih antirodnih pokreta (austrijski, belgijski, hrvatski, francuski, njemački, talijanski, poljski, ruski, slovenski i španjolski), jednu vladinu antirodnu politiku (Mađarska) i jedan izostanak antirodnih pokreta (Irska). Komparativnom analizom autori su utvrdili ciljeve kojima pokreti teže, glavne vrste aktera i strategije koje su najčešće koristili. Pišući o iznijansiranosti "globalne desnice" i uspoređujući nacionalne antirodne pokrete, Paternotte i Kuhar (2018) tvrde kako se mobilizacija protiv "rodne ideologije" razlikuje od desnog populizma. Riječ je o često međusobno natjecateljskim fenomenima koji se u specifičnoj situaciji ponekad povežu.

Analizirajući iste nacionalne pokrete, Kuhar i Zobec (2017) uspoređuju vrste antirodnih mobilizacija kojima je cilj opstrukcija obrazovnog procesa $\mathrm{u}$ javnim školama. Mobilizacije prikazuju na temelju analize roditeljskih skupina koje vrše pritisak na škole, profesore i profesorice kako bi se iz nastavnog programa uklonila tema istospolnih zajednica, rodnih uloga i spolnog odgoja. Aktivnosti roditeljskih skupina dijele na opće prosvjede protiv spolnog odgoja, osuđivanje udžbenika koji promiču "rodnu ideologiju" i organiziranje masovnih prosvjeda kako bi djeca mogla izostati s nastave.
Komparativnu analizu koristi i Garbagnoli (2016), koja je proučavala prijenos vatikanske retorike o "rodnoj ideologiji" $\mathrm{u}$ antirodne demonstracije u Francuskoj i Italiji. Roggeband i Krizsán (2018) mapiraju obrasce nazadovanja rodno ravnopravnih politika komparativnom analizom hrvatskoga, mađarskog i poljskog slučaja. Glavne uzroke nazadovanja autorice vide u napadima i opoziciji vladinoj politici rodne ravnopravnosti, koji su se u respektivnim državama očitovali u propasti politika rodne ravnopravnosti, potkopavanja primjene tih politika i eroziji mehanizama savjetovanja. U proširenoj inačici svoga članka, Krizsan i Roggeband (2018) uspoređuju procese nazadovanja politika rodne ravnopravnosti u Hrvatskoj, Mađarskoj, Poljskoj i Rumunjskoj, kao i feminističke odgovore na ta nazadovanja. Procese nazadovanja dijele na diskurzivnu delegitimaciju ciljeva rodne politike, urušavanje i preoblikovanje postojećih politika, podrivanje implementacije i eroziju odgovornosti, dok feminističke odgovore na nazadovanja klasificiraju kao disruptivne prosvjede, nove obrasce izgradnje koalicije te mirovanje i propast ženskih pokreta.

Grzebalska i Pető (2018) pokazuju svojom komparativnom analizom ideoloških stupova i politika neliberalnih vladajućih stranaka u Mađarskoj i Poljskoj kako je suvremena neliberalna transformacija političkog sustava proces koji se oslanja na politiku roda. Neliberalne demokracije utemeljene su na suprotstavljanju paradigmi liberalne ravnopravnosti, provođenju obiteljski osviještenih i antirodnih politika te na prisvajanju ključnih koncepata, alata i kanala financiranja liberalnih politika ravnopravnosti.

\section{Zemljopisna pokrivenost istraživanjima}

Najviše radova (16) bavilo se analizom poljskoga, potom talijanskoga (12), ma- 
đarskoga (10) i francuskoga (8) i hrvatskoga (6) antirodnog pokreta. Sljedećim valom istraživanja bili su obuhvaćeni austrijski i njemački (po 5), slovenski, španjolski i slovački (po 4) te belgijski, irski, ruski i brazilski antirodni pokret i diskurs (po 3 rada). U 62 članka analizirano je 29 nacionalnih antirodnih pokreta, što dokazuje proširenost pokreta, ali i raznolikost akademskog interesa za njih.

U 47 slučajeva istraživači su proučavali nacionalne pokrete istočne i jugoistočne Europe. Riječ je o broju analitičkih slučajeva - neki su nacionalni pokreti analizirani češće pa je tako poljski pokret analiziran šesnaest puta - a ne na broj nacionalnih pokreta. U 43 slučaja proučavani su pokreti u zapadnoj Europi, samo u osam slučajeva u Latinskoj Americi, dva u Sjevernoj Americi i jedan u Africi. Grupiranjem antirodnih pokreta po učestalosti i regijama postaje očitim da su analize pokreta u istočnoj, jugoistočnoj i zapadnoj Europi činile gotovo 90 posto svih istraživanja. S obzirom na unaprijed sužen korpus analiziranih radova uzrokovan uporabom engleske sintagme u pretraživanjima, očekivana je premoć članaka o antirodnim pokretima u Europi, kao što je vidljiv nedostatak publikacija na engleskom jeziku o antirodnim pokretima globalnog Juga.

\section{Zaključak}

Pregled radova o antirodnim pokretima ukazuje na nekoliko ključnih obilježja istraživanja toga fenomena. Prvo, istraživanja su vrlo heterogena. Tom se temom bave različite akademske discipline, zaokuplja mnogo autora i autorica, a teorijsko je pojmovlje neusuglašeno. $\mathrm{Na}$ heterogenost polja istraživanja ukazuje i raznolikost časopisa u kojima su radovi o toj temi objavljeni. Većina časopisa objavila je samo jedan članak, a nekoliko je objavilo više članaka u sklopu poseb- nih izdanja. S obzirom na disciplinarnu heterogenost, u radovima se koriste vrlo različita određenja istraživanog fenomena, koja se mogu svrstati u četiri široke kategorije: (a) antirodni pokreti, (b) antifeministički pokreti, (c) radikalna, populistička, ekstremna i/ili religijska desnica, (d) heteroaktivizam i neliberalna demokracija.

Drugo, istraživanja su homogena samo prema korištenim metodama i zemljopisnoj pokrivenosti. Prevladavaju kvalitativne metode istraživanja među kojima je najčešća kritička analiza diskursa. Najčešće su analizirane regije istočna, jugoistočna i zapadna Europa, dok nedostaju radovi o antirodnim pokretima globalnog Juga.

Treće, u manje od petine radova antirodni pokreti definirani su kao društveni pokreti. Analitički pristupi društvenim pokretima i politikama osporavanja oslanjali su se najviše na kulturne artefakte i uokvirivanja, među kojima su se najčešće analizirali diskurzivni okvir "rodne ideologije" i antikolonijalni okvir. Drugi najčešći pristup usmjeravao se na analizu aktivističkih mreža, a najviše je bio usredotočen na ulogu Katoličke crkve i radikalnih desnih političkih stranaka. Najmanje je korišten je analitički pristup strukture političkih mogućnosti.

Glavni fokus budućih istraživanja trebao bi biti u primjeni komparativnih istraživanja, kako u određenoj regiji tako i među različitim regijama. Unatoč tome što neka komparativna istraživanja postoje, još uvijek nedostaje komparativnih analiza Latinske Amerike, srednje i jugoistočne Europe. Nedostaju i istraživanja raznih aktera unutar antirodnih pokreta, posebice neformalnih inicijativa i novoosnovanih grupacija. Dosadašnja su istraživanja uvelike bila usredotočena na institucionalne aktere, poput Katoličke crkve i radikalnih desnih stranaka. No, kako su Kuhar i Pa- 
ternotte (2017) naveli, antirodne pokrete čine kompleksne konstelacije aktera. Fokusiranje na novonastale skupine koje djeluju izvan institucija, poput inicijativa protiv pobačaja, daje potencijal za objašnjavanje razloga i načina ostvarivanja visoke razine mobilizacije unutar lokalnih zajednica. Buduća istraživanja trebala bi, naposljetku, obuhvatiti potražnju, to jest razloge podrške antirodnim pokretima u općoj populaciji. Osim jednoga istraživanja o stavovima poljskih katolika (Marchlewska i dr.
2019), analizirani radovi bave se ponudom pokreta na temelju analize priopćenja, govora vodećih osoba unutar pokreta ili objava na društvenim mrežama. Analitički fokus potražnje trebao bi biti na prisutnosti i proširenosti antirodnih stavova u stanovništvu, povezanosti s religijskom identifikacijom i izbornim ponašanjem pojedinaca. Navedena bi se analiza mogla provesti korištenjem inovativnih metoda, poput anketa kojima bi se ispitali stavovi sudionika antirodnih prosvjeda. 


\section{Literatura}

Bandelli, Daniela. 2017. Femicide, Gender and Violence: Discourses and Counterdiscourses in Italy. Basingstoke: Palgrave Macmillan. DOI: 10.1007/978-3-319-47785-5

Bracke, Sarah, Dupont, Wannes, Paternotte, David. 2017. "No Prophet is Accepted in His Own Country": Catholic Anti-Gender Activism in Belgium. U: Kuhar, Roman, Paternotte, David. (ur.). Anti-Gender Campaigns in Europe: Mobilizing against Equality. London; New York: Rowman \& Littlefield Publishers, str. 41-58.

Browne, Kath, Nash, Catherine J. 2017. Heteroactivism: Beyond Anti-Gay. ACME: An International Journal for Critical Geographies. (16) 4: 654-652.

Buschmann, Dovainè. 2017. Worse than Communism? Discursive Anti-Gender Mobilizations in Lithuania. Informacijos mokslai. (80): 31-49. DOI: 10.15388/Im.2017.80.11670

Buss, Doris E. 1998. Robes, Relics and Rights: The Vatican and the Beijing Conference On Women. Social \& Legal Studies. (7) 3: 339-63. DOI: 10.1177/096466399800700302

Butler, Judith. 2019a. Anti-Gender Ideology and Mahmood's Critique of the Secular Age. Journal of the American Academy of Religion. (87) 4: 955-67. DOI: $10.1093 /$ jaarel/lfz083

Butler, Judith. 2019b. What Threat? The Campaign Against 'Gender Ideology.' Glocalism: Journal of culture, politics and innovation. (3): 1-12. DOI: 10.12893/gjcpi.2019.3.1

Carnac, Romain. 2020. Imaginary Enemy, Real Wounds: Counter-Movements, 'Gender Theory', and the French Catholic Church. Social Movement Studies. (19) 1: 63-81. DOI: 10.1080/14742837.2019.1708307

Case, Mary Anne. 2019. Trans Formations in the Vatican's War on 'Gender
Ideology.' Signs: Journal of Women in Culture and Society. (44) 3: 639-64. DOI: $10.1086 / 701498$

Corredor, Elizabeth S. 2019. Unpacking 'Gender Ideology' and the Global Right's Antigender Countermovement. Signs: Journal of Women in Culture and Society. (44) 3: 613-38. DOI: 10.1086/701171

Diani, Mario. 1992. The Concept of Social Movement. The Sociological Review. (40) 1: 1-25. DOI: 10.1111/j.1467-954X.1992.tb02943.x

Donà, Alessia. 2020. The Populist Italian Lega from Ethno-Regionalism to Radical Right-Wing Nationalism: Backsliding Gender-Equality Policies with a Little Help from the Anti-Gender Movement. European Journal of Politics and Gender. 3 (1): 161-3. DOI: 10. 1332/251510819X15657567135115

Garbagnoli, Sara. 2016. Against the Heresy of Immanence: Vatican's 'Gender' as a New Rhetorical Device Against the Denaturalization of the Sexual Order. Religion and Gender. (6) 2: 187-204. DOI: 10.18352/rg.10156

Garbagnoli, Sara. 2017. Italy as a Lighthouse: Anti-Gender Protests between the" Anthropological Question "and National Identity. U: Kuhar, Roman, Paternotte, David. (ur.). Anti-Gender Campaigns in Europe: Mobilizing against Equality. London; New York: Rowman \& Littlefield Publishers, str. 151-74.

Gennero, Valeria. 2017. 'This Town Is Against Gender': Bending Gender in Italian Culture. Review of International American Studies. (10) 2: 105-20.

Goldstone, Jack A., Tilly., Charles. 2001. Threat (and Opportunity): Popular Action and State Response in the Dynamics of Contentious Action. U: Aminzade, Ronald R., et al. Silence and Voice in the Study of Conten- 
tious Politics. Cambridge: Cambridge University Press, str. 179-94. DOI: 10.1017/CBO9780511815331

Goodwin, Jeff, Jasper, James M. (ur.). 2015. The Social Movements Reader: Cases and Concepts. Chichester, West Sussex: John Wiley \& Sons.

Graff, Agnieszka. 2014. Report from the Gender Trenches: War against 'Genderism' in Poland. European Journal of Women's Studies. (21) 4: 431-35. DOI: $10.1177 / 1350506814546091$

Graff, Agnieszka, Korolczuk. Elżbieta. 2017. "Worse than Communism and Nazism Put Together": War on Gender in Poland. U: Kuhar, Roman, Paternotte, David. (ur.). Anti-Gender Campaigns in Europe: Mobilizing against Equality. London; New York: Rowman \& Littlefield Publishers, str. 175-94.

Grzebalska, Weronika, Pető, Andrea. 2018. The Gendered Modus Operandi of the Illiberal Transformation in Hungary and Poland. Women's Studies International Forum. (68): 164-72. DOI: 10.1016/j.wsif.2017.12.001

Harsin, Jayson. 2018a. Post-Truth Populism: The French Anti-Gender Theory Movement and Cross-Cultural Similarities. Communication, Culture and Critique. (11) 1: 35-52. DOI: 10.1093/ $\mathrm{ccc} / \mathrm{tcx} 017$

Harsin, Jayson. 2018b. Tactical Connecting and (Im-)Mobilizing in the French Boycott School Day Campaign and Anti-Gender Theory Movement. U: Peeren, Esther, et al. (ur). Global Cultures of Contestation: Mobility, Sustainability, Aesthetics \& Connectivity. Cham: Springer International Publishing, str. 193-214. DOI: 10.1007/9783-319-63982-6

Hennig, Anja. 2018. Political Genderphobia in Europe: Accounting for Right-Wing Political-Religious Alliances against Gender-Sensitive Educa- tion Reforms since 2012. Zeitschrift für Religion, Gesellschaft und Politik. (2) 2: 193-219. DOI: 10.1007/s41682018-0026-X

Hodžić, Amir, Štulhofer, Aleksandar. 2017. Embryo, Teddy Bear-Centaur and the Constitution: Mobilizations against "Gender Ideology" and Sexual Permissiveness in Croatia. U: Kuhar, Roman, Paternotte, David. (ur.). Anti-Gender Campaigns in Europe: Mobilizing against Equality. London; New York: Rowman \& Littlefield Publishers, str. 59-78.

Kalil, Isabela Oliveira. 2019. 'Gender Ideology' Incursions in Education. Sur - International Journal on Human Rights. (16) 29: 115-123.

Kaoma, Kapya. 2016. The Vatican AntiGender Theory and Sexual Politics: An African Response. Religion and Gender. (6) 2: 282-92. DOI: 10.18352/ rg. 10180

Korolczuk, Elżbieta. 2020. The Fight against 'Gender' and 'LGBT Ideology': New Developments in Poland. European Journal of Politics and Gender. (3) 1: 165-67. DOI: 10.1332/2515108 19X15744244471843

Korolczuk, Elżbieta, Graff, Agnieszka. 2018. Gender as 'Ebola from Brussels': The Anticolonial Frame and the Rise of Illiberal Populism. Signs: Journal of Women in Culture and Society. (43) 4: 797-821. DOI: 10.1086/696691

Kortendiek, Beate, Riegraf, Birgit, Sabisch, Katja. (ur.). 2019. Handbuch Interdisziplinäre Geschlechterforschung. Wiesbaden: Springer Fachmedien, DOI: 10.1007/978-3-658-12496-0

Köttig, Michaela, Bitzan, Renate, Petö, Andrea. (ur.). 2017. Gender and Far Right Politics in Europe. Cham: Springer International Publishing. DOI: 10.1007/978-3-319-43533-6

Kováts, Eszter. 2017. The Emergence of Powerful Anti-Gender Movements 
in Europe and the Crisis of Liberal Democracy. U: Köttig, Michaela, Bitzan, Renate, Petö, Andrea. (ur.). Gender and Far Right Politics in Europe. Cham: Springer International Publishing, str .175-89. DOI: 10.1007/9783-319-43533-6

Kováts, Eszter. 2018. Questioning Consensuses: Right-Wing Populism, Anti-Populism, and the Threat of 'Gender Ideology.' Sociological Research Online. (23) 2: 528-38. DOI: $10.1177 / 1360780418764735$

Kováts, Eszter, Pető, Andrea. 2017. Anti-Gender Discourse in Hungary: A Discourse Without a Movement. U: Kuhar, Roman, Paternotte, David. (ur.). Anti-Gender Campaigns in Europe: Mobilizing against Equality. London; New York: Rowman \& Littlefield Publishers, str. 117-31.

Kriesi, Hanspeter. 2013. Društveni pokreti. U: Caramani, Daniele. (ur.). Komparativna politika. Zagreb: Fakultet političkih znanosti, str. 291-308.

Krizsan, Andrea, Roggeband, Conny. 2018. Towards a Conceptual Framework for Struggles over Democracy in Backsliding States: Gender Equality Policy in Central Eastern Europe. Politics and Governance. (6) 3: 90-100. DOI: 10.17645/pag.v6i3.1414

Kuhar, Roman. 2017. Changing Gender Several Times a Day: The Anti-Gender Movement in Slovenia. U: Kuhar, Roman, Paternotte, David. (ur.). Anti-Gender Campaigns in Europe: Mobilizing against Equality. London; New York: Rowman \& Littlefield Publishers, str. 215-32.

Kuhar, Roman, Paternotte, David. (ur.). 2017. Anti-Gender Campaigns in Europe: Mobilizing against Equality. London; New York: Rowman \& Littlefield Publishers.

Kuhar, Roman, Zobec, Aleš. 2017. The Anti-Gender Movement in Europe and the Educational Process in Public Schools. Center for Educational Policy Studies Journal. (7) 2: 29-46.

Lavizzari, Anna, Prearo, Massimo. 2018. The Anti-Gender Movement in Italy: Catholic Participation between Electoral and Protest Politics. European Societies. (21) 3: 422-42. DOI: 10.1080/14616696.2018.1536801

Marchlewska, Marta et al. 2019. In Search of an Imaginary Enemy: Catholic Collective Narcissism and the Endorsement of Gender Conspiracy Beliefs. The Journal of Social Psychology. (159) 6: 766-79. DOI: 10.1080/00224545.2019.1586637

McAdam, Doug, McCarthy, John D., Zald, Mayer N. 1996. Comparative Perspectives on Social Movements: Political Opportunities, Mobilizing Structures, and Cultural Framings. Cambridge: Cambridge University Press. DOI: $10.1017 / \mathrm{CBO} 9780511803987$

Mehta, Sandhya Rao. (ur.). 2018. Language and Literature in a Glocal World. Singapore: Springer. DOI: 10.1007/978-981-10-8468-3

Miskolci, Richard. 2018. The Moral Crusade on 'Gender Ideology': Notes on Conservative Political Alliances in Latin America. Sociologies in Dialogue. (4) 2: 44-59. DOI: 10.20336/ sid.v4i2.99

Odrowąż-Coates, Anna. 2015. Gender Crisis in Poland, Catholic Ideology and the Media. Sociology Mind. (5) 1: 27-34. DOI: 10.4236/sm.2015.51004

Olteanu, Tina. 2017. Gender Relations and the Freedom Party of Austria (FPÖ). Perspectives in Politics / Perspective Politice. (10) 1: 75-81.

Paternotte, David, Kuhar, Roman. 2018. Disentangling and Locating the 'Global Right': Anti-Gender Campaigns in Europe. Politics and Governance. (6) 3: 6-19. DOI: 10.17645/pag.v6i3.1557 
Peeren, Esther, et al. (ur). 2018. Global Cultures of Contestation: Mobility, Sustainability, Aesthetics \& Connectivity. Cham: Springer International Publishing. DOI: 10.1007/978-3-319-63982-6

Perintfalvi, Rita. 2016. The True Face of the 'Gender Ideology' Discourse: Religious Fundamentalism, or Questioning the Principle of Democracy? Journal of the European Society of Women in Theological Research. (24): 47-62. DOI: 10.2143/ ESWTR.24.0.3170025

Petö, Andrea. 2016. How Are Anti-Gender Movements Changing Gender Studies as a Profession? Religion and Gender. (6) 2: 297-99. DOI: 10.18352/ rg. 10182

Pető, Andrea. 2019. Eastern Europe: Gender Research, Knowledge Production and Institutions. U: Kortendiek, Beate, Riegraf, Birgit, Sabisch, Katja. (ur.). Handbuch Interdisziplinäre Geschlechterforschung. Wiesbaden: Springer Fachmedien, str. 1535-45. DOI: 10.1007/978-3-658-12496-0

Raos, Višeslav. 2018. From Pontida to Brussels: The Nationalization and Europeanization of the Northern League. Anali Hrvatskog politološkog društva, (15) 1: 105-125. DOI: 10.20901/an.15.05

Roggeband, Conny. 2018. The Good, the Bad, and the Ugly: Making Sense of Opposition to Feminisms from a Social-Movement Perspective. U: Verloo, Mieke. (ur.). Varieties of Opposition to Gender Equality in Europe. Routledge, str. 19-37. DOI: $10.4324 / 9781315625744$

Roggeband, Conny, Krizsán, Andrea. 2018. Reversing Gender Policy Progress: Patterns of Backsliding in Central and Eastern European New Democracies. European Journal of Gender and Politics. (1) 3:367-85. DOI: 10 $.1332 / 251510818 X 15311219732356$
Snow, David, Benford, Robert. 1992. Master Frames and Cycles of Protest. U: Morris, Aldon D., McClurg Mueller, Carol. (ur.). Frontiers in Social Movement Theory. London: Yale University Press, str. 133-155.

Spallaccia, Beatrice. 2019. Ideologia Del Gender: Towards a Transcultural Understanding of the Phenomenon. Modern Italy. (25) 2: 1-15. DOI: $10.1017 /$ mit.2019.63

Szelewa, Dorota. 2014. The Second Wave of Anti-feminism? Post-crisis Maternalist Policies and the Attack on the Concept of Gender in Poland. Gender rovné príležitosti výzkum. (15) 2: 33-47. DOI: 10.13060/12130028.2014.15.2.129

Tarrow, Sidney. 2011. Power in Movement: Social Movements and Contentious Politics. Cambridge: New York: Cambridge University Press. DOI: 10.1017/CBO9780511973529

Velmet, Aro. 2019. Sovereignty after Gender Trouble: Language, Reproduction, and Supranationalism in Estonia, 19802017. Journal of the History of Ideas. (80) 3: 455-78. DOI: 10.1353/jhi.2019.0027

Verloo, Mieke. 2018a. Gender Knowledge, and Opposition to the Feminist Project: Extreme-Right Populist Parties in the Netherlands. Politics and Governance. (6) 3: 20-30. DOI: 10.17645/pag.v6i3.1456

Verloo, Mieke. (ur.). 2018b. Varieties of Opposition to Gender Equality in Europe. Routledge. DOI: 10.4324/9781315625744

Verloo, Mieke, Paternotte, David. 2018. The Feminist Project under Threat in Europe. Politics and Governance. (6) 3: 1-5. DOI: 10.17645/pag.v6i3.1736

Wallerstein, Immanuel. 1997. Eurocentrism and Its Avatars: The Dilemmas of Social Science. Sociological Bulletin. (46) 1: 21-39. DOI: 10.1177/0038022919970102 


\section{Anti-Gender Movements in $21^{\text {st }}$ Century}

Abstract The beginning of the $21^{\text {st }}$ century was marked by the emergence and geographical spread of anti-gender movements in Europe and Latin America. The analysed research articles were selected through the Google Scholar academic search engine with the basic criterion for inclusion in the analysis being the mention of the term 'anti-gender' in the title, abstract, or the body of the text. Sixty-two papers on the subject of anti-gender movements have been included in the analysis, and the review is structured according to the main analytical approaches in social movements studies: regarding cultural artefacts and discursive frames, organizational characteristics and activist networks, and the structure of political opportunities. The article also analyses the conceptual definitions, the methods used, and the geographical coverage of the research. Based on the content analysis the author concludes the presence of heterogeneity in terms of the conceptual definition, homogeneity when it comes to methods and geographical coverage, and the prevalence of cultural artefacts and discursive frameworks when analysing anti-gender movements.

Key words social movements, gender ideology, anti-gender movements, contentious politics, radical right

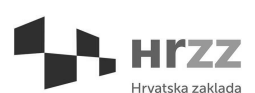
Hrvatska zakla
zaznanost 1. Hrzz Croatian Science
Foundation
Rad doktoranda Maje Gergorić financiran/sufinanciran je iz "Projekta razvoja karijera mladih istraživača - izobrazba novih doktora znanosti" Hrvatske zaklade za znanost

The work of doctoral student Maja Gergorić has been fully supported/supported in part by the "Young researchers' career development project - training of doctoral students" of the Croatian Science Foundation 
